January 2010

\title{
Predictors of emotional problems and physical aggression among children of Hong Kong Chinese, Mainland Chinese and Filipino immigrants to Canada
}

\author{
Morton Beiser \\ Ryerson University, \\ Hayley Hamilton \\ University of Toronto \\ Joanna Anneke Rummens \\ Hospital for Sick Children Toronto \\ Jacqueline Oxman-Martinez \\ Universite' de Montre'al \\ Linda Ogilvie \\ University of Alberta
}

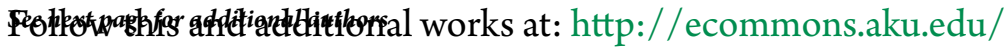
eastafrica_fhs_mc_paediatr_child_health

Part of the Pediatrics Commons

\section{Recommended Citation}

Beiser, M., Hamilton, H., Rummens, J. A., Oxman-Martinez, J., Ogilvie, L., Humphrey, C., Armstrong, R. (2010). Predictors of emotional problems and physical aggression among children of Hong Kong Chinese, Mainland Chinese and Filipino immigrants to Canada. Social Psychiatry and Psychiatric Epidemiology, 45(10), 1011-1021.

Available at: http://ecommons.aku.edu/eastafrica_fhs_mc_paediatr_child_health/58 


\section{Authors}

Morton Beiser, Hayley Hamilton, Joanna Anneke Rummens, Jacqueline Oxman-Martinez, Linda Ogilvie, Chuck Humphrey, and Robert Armstrong 


\title{
Predictors of emotional problems and physical aggression among children of Hong Kong Chinese, Mainland Chinese and Filipino immigrants to Canada
}

\author{
Morton Beiser - Hayley Hamilton · Joanna Anneke Rummens · \\ Jacqueline Oxman-Martinez $\cdot$ Linda Ogilvie $\cdot$ Chuck Humphrey · \\ Robert Armstrong
}

Received: 23 December 2008/Accepted: 3 September 2009/Published online: 19 September 2009

(c) Springer-Verlag 2009

\begin{abstract}
Background and study aims Data from the New Canadian Children and Youth Study (NCCYS), a national study of immigrant children and youth in Canada, are used to examine the mental health salience of putatively universal determinants, as well as of immigration-specific factors. Universal factors (UF) include age, gender, family and neighbourhood characteristics. Migration-specific (MS) factors include ethnic background, acculturative stress, prejudice, and the impact of region of resettlement within Canada.

Methods In a sample of children from Hong Kong, the Philippines and Mainland China, the study examined the determinants of emotional problems (EP), and physical aggression (PA). A two-step regression analysis entered UF on step 1, and MS variables on step 2.
\end{abstract}

M. Beiser $(\bowtie)$

Department of Psychology, Ryerson University, JOR-1016, 350 Victoria St., Toronto, ON M5B2K3, Canada e-mail: mail@mortonbeiser.com

\section{Beiser}

Ontario Metropolis Centre of Excellence for Research on Immigration and Settlement, Toronto, ON, Canada

\section{Beiser}

Cultural Pluralism and Health, University of Toronto,

Toronto, ON, Canada

\section{H. Hamilton}

Department of Psychiatry, University of Toronto, Toronto, ON, Canada

J. A. Rummens

Child Health Evaluation Sciences, Hospital for Sick Children

Toronto, Toronto, ON, Canada
Results Universal factors accounted for $12.1 \%$ of EP variance. Addition of MS variables increased explained variance to $15.6 \%$. Significant UF predictors: parental depression, family dysfunction, and parent's education. Significant MS variables: country of origin, region of resettlement, resettlement stress, prejudice, and limited linguistic fluency. UF accounted for $6.3 \%$ of variance in PA scores. Adding migration-specific variables increased variance explained to $9.1 \%$. UF: age, gender, parent's depression, family dysfunction. MS: country of origin, region of resettlement, resettlement stress, and parent's perception of prejudice.

Conclusions Net of the effect of factors affecting the mental health of most, if not all children, migration-specific variables contribute to understanding immigrant children's mental health.

\footnotetext{
J. Oxman-Martinez

École de service social, Université de Montréal,

Montreal, QC, Canada

L. Ogilvie

Faculty of Nursing, University of Alberta,

Edmonton, AB, Canada

C. Humphrey

Data Library, University of Alberta,

Edmonton, AB, Canada

R. Armstrong

Department of Pediatrics, University of British Columbia,

Vancouver, BC, Canada
} 
Keywords Immigrant children - Emotional disorder . Physical aggression $\cdot$ Ethnicity $\cdot$ Regional effects

\section{Introduction}

Helping the children of new settlers adapt to their schools, integrate with the larger society and stay happy and healthy during the process are important goals for all immigrant receiving countries. However, the current dearth of knowledge about what promotes adaptation and integration and what jeopardizes the well-being of immigrant and refugee children hampers the development of effective policy and practice $[11,16,51]$.

To help rectify the situation, information is required about the extent to which factors that seem to affect the mental health of most, if not all children, are also salient for children in immigrant families. There is also a need to identify risk and protective factors unique to the experience of children in immigrant families. The New Canadian Children and Youth Study (NCCYS) is a longitudinal investigation of personal and contextual factors affecting immigrant children's mental health. The current report, based on data from the study's initial survey, has four major objectives: (1) explore the extent to which determinants of mental health for children in general are also relevant for immigrant children, (2) identify which, if any immigration and settlement experiences affect the mental health of immigrant children, (3) explore the mental health salience of place of resettlement, (4) demonstrate the importance of unpacking overly inclusive categories such as "Asian immigrants."

\section{Background}

One in five children living in Canada was born either outside the country or to recently arrived immigrants $[16$, 48]. Insights gleaned from studying children in the general population (see for example [49]) probably tell only part of the story about immigrant children and their mental health. Migration and resettlement create unique challenges that call for the development of special personal and social resources to meet them.

Mental health is the product of interactions among personal factors such as age, gender, and ethnicity, and ecological influences, such as household characteristics, income, parental mental health, family functioning, and neighborhood quality [15]. Since the mental health salience of a risk factor such as poverty and a protective factor such as good family functioning has been repeatedly confirmed, it is hard to imagine omitting them from any serious inquiry into children's well-being. In acknowledgement of this history, the current report alludes to these factors as mental health "universals." However, since one can never be sure that anything is truly universal, we add the adjective "putative." Over and above the challenges all children face, immigrant children have to deal with relatively unique stressors, and they may benefit from relatively specific protective factors $[7,16,27,32,40]$. The current report explores the mental health salience of both putatively universal and immigration-specific processes.

Bronfenbrenner's [15] concept of nested ecological systems provides a theoretical framework within which to identify factors ranging from the micro- to the macrosystem level that can affect mental health. Parental depression, a proximal, microsystem variable, jeopardizes the mental health of both native-born [22, 29, 41, 54, 55] and immigrant children [40]. Among children in the general population, poverty has a directly deleterious effect on mental health, as well as indirect effects through linkages with ineffective parenting, parental psychopathology, intrafamilial hostility, single parent families, and overcrowded housing [55, 56]. According to Canadian studies [7, 27], poverty affects immigrant children, just as it does their majority culture counterparts. However, the effect is smaller, probably because poverty among immigrants is less likely to be linked to single parent families or intrafamilial hostility [7].

More than one-third of adult immigrants speak neither English nor French on arrival in Canada [48]. Research [58] suggests that parental inability to speak the language of the receiving society jeopardizes children's mental health. One possible reason is that lack of linguistic fluency impedes parent's ability to take part in their children's socialization, most particularly in their schools [58]. Another problem is that children's ability to learn a new language more quickly than their parents can create role reversal, a situation in which children are called upon to negotiate with the larger society on their parent's behalf, thereby being forced into assuming roles usually reserved for adults [16, 32, 39]. More distal factors, such as dysfunctional neighbourhoods have been implicated as mental health risk factors for all children [23, 28]. Although not exclusive to the immigrant experience, prejudice is a mental health challenge confronted by many immigrant children. One in five children of new settlers-particularly those who belong to visible minority groups-reports encounters with discrimination and prejudice during their resettlement in Canada [4, 9, 10, 42]. On the protective side of the ledger, the like-ethnic community, so important to maintaining the well-being of adult refugees in resettlement countries [9] is a possible mental health resource for their children as well. 
Countries, and even regions within a country, offer newcomers differing "levels of hospitality," that is macrosocial climates that can affect mental health $[3,9,16]$. Inter-provincial disparities in the amounts of money spent per immigrant $[16,20]$ translate into differential access to language training, day care, job training programs and health care, each of which may affect the well-being of parents and children. Investigations focusing on newcomer children often employ overly broad categories such as "Asian immigrant [27]." One of the aims of the current study is to demonstrate the importance of unpacking such categories. To do so, country of origin is used as an admittedly imperfect proxy for ethnocultural background. This is not meant to imply that people from a particular country of origin are ethnically homogeneous, but rather that people coming from different countries have been exposed to relatively unique cultural influences during their pre-migration lives, that they follow different routes to get to Canada, and that country of origin affects the reception given to them on arrival.

The present report is concerned with children and their families from three different immigrant groups-Hong Kong (HK) Chinese, Mainland (PRC) Chinese and Filipino. Although immigrants have been coming from Hong Kong to Canada since the late nineteenth century, the flow increased dramatically during the 1980s and early 1990s, in anticipation of the 1997 UK handover of Hong Kong to China. Although most Hong Kong Chinese families entered Canada under the country's "point system," under which immigration applicants can be admitted if they achieve a certain score based on factors such as education, English and French language fluency, occupational skills, and presence of family members in Canada, some applied for admission under Canada's entrepreneurial class, a special category designed to attract people with financial skills and resources [20]. Although they acquired Canadian citizenship, many families chose to retain HK citizenship in order to pursue business opportunities at home. The socalled "astronaut" or transnational family, in which parents spend long periods of time in Hong Kong while the children stay in Canada in the care of domestic help, has been a product of these opportunities and choices [35, 44, 45, 52]. International emigration from Mainland China began in the early 1980s, after the relaxation of tensions between the Peoples Republic of China (PRC) and the west. In comparison with their Cantonese-speaking counterparts from Hong Kong, PRC Chinese immigrants are more likely to speak Mandarin, have fewer economic resources, and live in more residentially stable families [19, 20, 36, 37]. Both HK and PRC Chinese live in Canada's largest cities, where they remain the most residentially segregated of all of Canada's visible minority groups [48]. Most $(60 \%)$ of Philippines-origin immigrants are women, and most-because of the century-long US presence in their country-were educated in English [17, 18]. Canada's shortage of nurses and of trained personnel to care for children and the elderly created a portal of entry that attracted many Filipina immigrants. The country's Live-inCaregiver program provides fast tracking to permanent resident status in return for an initial 24 months of paid service as a caregiver for children or the elderly. The Filipino pattern of immigration gives rise to transnational families very different from HK "astronauts." Filipino immigrants often come alone, share wages with family left behind, and then, after achieving permanent resident status, sponsor family members to join them $[1,2,17,18,34]$.

Despite inter-group differences, Asian immigrants are highly likely to experience prejudice as a common problem. As many as $25 \%$ of Asian immigrants report encounters with prejudice within the first 10 years of resettling in Canada [4, 9, 10, 42]. Aside from visible minority status, the social construction of immigrant is freighted with negative attributions [9].

\section{Methods}

The NCCYS is a longitudinal study, with two age-defined inception cohorts: children 4-6, and children 11-13. Children in the sample were either born abroad or into families in which at least one parent had immigrated to Canada within a 10-year period prior to the study's inception. Since almost all immigrants settle in cities [48], samples were recruited from the major cities in four federally defined regions: Vancouver, in the Pacific region; Edmonton, Calgary and Winnipeg, Western region; Toronto, Central region; and Montreal, Eastern region.

\section{Study sample}

A sub-study of the NCCYS, the current investigation aimed to recruit a sample of 180 children in each region, stratified to provide equal numbers by ethnicity, and age-group (4-6 and 11-13), for a total of 2,160. A number of strategies recommended for difficult to identify, hard to find, and highly mobile groups $[50,53]$ were employed. In the six cities, representatives from each of the targeted ethnocultural groups were invited to become members of Community Advisory Councils (CAC). After privately identifying families from their respective communities who fit NCCYS inclusion criteria, CAC members contacted potential sample families to request permission to introduce a research team member to explain the study and to obtain written consent to participate. Each participant was asked to think of other families with children meeting the study's inclusion criteria. They were then asked to contact 
Table 1 Sample description

\begin{tabular}{|c|c|c|c|c|c|c|}
\hline & \multicolumn{3}{|l|}{$4-6$} & \multicolumn{3}{|c|}{$11-13$} \\
\hline & Male & Female & Total & Male & Female & Total \\
\hline Mainland Chinese & 175 & 186 & 361 & 195 & 192 & 387 \\
\hline Hong Kong Chinese & 134 & 140 & 274 & 167 & 154 & 321 \\
\hline Filipino & 179 & 164 & 343 & 187 & 158 & 345 \\
\hline Total & 488 & 490 & 978 & 549 & 504 & 1,053 \\
\hline
\end{tabular}

$N=2,031$

these families to request permission for contact by the research team.

As Table 1 shows, the sample fell slightly short of its recruitment goals, particularly in its representation of the younger and the Hong Kong Chinese cohorts. Based on a population model using 2001 census data, each sample was weighted to the Census Subdivision (CSD) level. The CSD is usually a provincially defined municipality.

\section{Measures}

The NCCYS questionnaire elicits information about parental ethnic and religious backgrounds, parents' education, labor force activity, income, health status, family functioning, parenting behaviors, social support, neighborhood characteristics, pre- and post-migration stressors, relationships with the like-ethnic community, relationships with larger societal institutions, the child's general health and developmental history, and indicators of emotional problems (EP) and physical aggression (PA).

Canada's National Longitudinal Study of Children and Youth (NLSCY) [49] provided a framework for the development of the NCCYS measures of mental health, as well as of many of the putatively universal risk and protective factors. CAC's in each of the study regions judged the acceptability, the likelihood of achieving appropriate translation, and face validity of each of the NLSCY items. The immigrant-specific portions of the NCCYS derive either from the immigrant mental health literature, or were developed by the NCCYS team. NLSCY-derived items that survived the preliminary selection process, together with the immigrant-specific items were assembled into a draft questionnaire, translated into each of the heritage languages, and then back-translated in order to uncover and resolve ambiguities. Before embarking on the survey, bilingual interviewers, many of whom were immigrant or refugee professionals, took part in a 2-day training session. To ensure standardization, one senior member of the investigative team assumed responsibility for training in all of the centres. Project personnel interviewed the person most knowledgeable (PMK) about the child. In most cases, this was the child's mother. Pilot testing with the draft questionnaires provided another opportunity to identify troublesome items and to resolve ambiguities. Items that survived the two-stage process of community consultation and pilot testing were retained for the study.

The dependent variables for this report are EP and PA. Predictors include sociodemographic variables, putatively universal mental health risk and protective factors, and migration-specific risk and protective factors. Reliability coefficients (Cronbach's alpha) were calculated for each scale. In order to help overcome the problem of missing data, response choices for the individual items making up a scale were averaged to form a continuous measure.

\section{Dependent variables}

(a) Emotional problems (EP), measured by an eight item scale derived from the Ontario Child Health Survey [5, 13, 14] and the NLSCY [49]. Each item has three forcedchoice responses: (1) (never or not true), (2) (sometimes or sometimes true), and (3) (often or very true). Sample items include: How often would you say that (index child) (i) seems unhappy, sad or depressed? (ii) not as happy as other children? Reliability coefficient 0.75 . Due to the use of item means rather than raw scores, scale scores range from 1 to 3, rather than 3 to 24. Mean 1.310, SD 0.296. (b) Physical aggression (PA), based on the same sources as EP [5, 13, 14, 49], contains six items, with stem question and forced-choice responses identical to the EP. Sample items include: (i) gets into many fights? and (ii) is cruel, bullies or is mean to others? Reliability coefficient 0.74 , range $1-3$, mean 1.165 , SD 0.255 .

\section{Putatively universal sociodemographic influences on mental health}

Variables include (a) age cohort (measured by a dummy variable, ref. category $=11-13$ ); (b) gender, (a dummy variable, ref. category = male); (c) parental education, PMK with university degree $=1$, lower than university degree $=0$; (d) parent's marital status: married $=1$, other $=0$.

\section{Putatively universal risk and protective factors}

Putatively universal mental health risk factors include: (a) low income-a measure of household income adequacy developed, and routinely used by Statistics Canada. Low income is defined as a household with 1-2 persons and a total income below $\$ 15,000$, or a $3-4$ person household with income below $\$ 20,000$, or a household with 5 or more persons and income below \$30,000. When household income was not reported, we used a dummy variable representing income missing. For both low income and 
missing income, the common reference groups is families above the low-income thresholds. This permitted us to retain cases with missing data, while avoiding unwarranted assumptions necessary for imputing values [57]. (b) PMK depression, based on forced-choice responses (rarely, sometimes, occasionally or most of the time) to 16 questions developed for use among Southeast Asian [6, 9]: the stem question is "Have you..." Item examples include: (i) been feeling unhappy? (ii) been feeling discouraged? (iii) low and hopeless? Reliability coefficient 0.90, range 1-3.75, mean 1.546, SD 0.444.

Putatively universal mental health protective factors included: (a) positive family functioning: fixed response categories for this 12 item scale [27, 49] range from 1 (strongly disagree) to 5 (strongly agree). Item examples include: (i) we express feelings to each other (ii) all members of the family are accepted regardless of their character. Reliability 0.85 , range $1-5$, mean 3.938, SD 0.392. (b) Neighbourhood cohesiveness: derived from the NLSCY [49], the scale contains five items, each with a response choice of 1 through 5 (strongly disagree to strongly agree). Item examples include: (i) if there is a problem around here, the neighbours get together to deal with it (ii) people around here are willing to help their neighbours. Reliability coefficient 0.81, range 1-5, mean 3.422, SD 0.540, and (c) PMK perceived social support: This seven item scale [49], has five forced-choice responses ranging from strongly agree to strongly disagree. Item examples include: (i) I have family and friends who help me feel safe, secure and happy (ii) there is someone I trust whom I would turn to for advice if I were having problems. Reliability coefficient 0.88 , range 1-5, mean 3.579, SD 0.588.

\section{Migration-specific sociodemographic, risk, and protective factors}

Migration-specific sociodemographic variables include: (a) country of origin, measured by dummy variables, (reference category $=$ Filipino); and (b) region of resettlement measured by dummy variables, (reference category = Toronto). Risk factors specific to the immigrant experience include: (a) PMK's ability to speak English or French fluently: responses for the sample as a whole were (Yes 24\%; no 76\%) (b) PMK resettlement stress: adapted from the Southeast Asian Refugee Resettlement Project [9] and further developed by working with community advisory groups, this scale contains seven items with responses ranging from never $=1$ to very often $=4$. The stem question is "How often have you felt stress because of...." Item examples: (i) I am living away from my family, relatives and friends (ii) I am unable to do the things I used to enjoy when I was in.... (country of origin). Reliability coefficient 0.90 , range $1-4$, mean 1.760 , SD 0.437 . (c)
PMK perception of prejudice. A six item scale, derived from the Refugee Resettlement Project [10, 42], with response choices from 1 through 5 (strongly disagree to strongly agree). Item examples include: (i) A lot of Canadians tend to look down on people from my country (ii) Landlords in Canada would rather rent an apartment to someone from another group than someone from my country. Reliability coefficient 0.80 , range $1-6$, mean 2.655, SD 0.583. The putative protective factor, like-ethnic neighbourhood concentration, was measured by one item, "This neighbourhood has many people from my country of origin," with five responses ranging from strongly agree to strongly disagree. The item was recorded as follows: strongly agree and agree $=$ Yes $(60 \%)$; all other responses $=$ No $(40 \%)$.

\section{Results}

Results described in Table 2 suggest differences in levels of emotional disorder and PA among children in the three ethnocultural groups, that PMK's from Hong Kong were less well-educated than their counterparts from the PRC and the Philippines, and that Filipino PMK's were more likely than the PMK's in the other two groups to be fluent in English or French. PRC and HK Chinese lived in more ethnically dense neighbourhoods than Filipinos. Compared to the two other groups, PRC households were more likely to be poor.

Predictive models were tested for each of the two dependent variables. The EP and PA scales, respectively, were regressed on demographic and on putatively universal risk and protective factors on step 1. Step 2 added immigration and resettlement-specific predictors including ethnicity and place of resettlement.

Table 3 examines results for EP. Model 1 accounted for $12.1 \%$ of the variance in scores. The addition of immigration-specific variables in Model 2 increased predictive power by $3.5 \%$. PMK depression and familial dysfunction made significant and independent contributions to EP. According to Model 2, HK children were at higher risk for EP than Filipino or PRC youngsters. PMK inability to speak one of Canada's official languages, resettlement stress, and perceptions of prejudice each increased the risk for children's EP. Region also made a difference. Children in Toronto were at higher risk for EP than children in Vancouver, Montreal or the Prairies.

Table 4 presents the results of regressing PA on the predictor variables. Model 1 accounts for $6.3 \%$ of the variance in risk of PA. Adding the immigrant-specific stress and protective variables in Model 2 improved the predictive power by almost $3 \%$. In contrast with EP, where child characteristics had no apparent effect, younger 
Table 2 Study variables by ethnic group

\begin{tabular}{|c|c|c|c|c|c|c|c|c|c|c|}
\hline & \multicolumn{3}{|c|}{ Mainland China } & \multicolumn{3}{|l|}{ Hong Kong } & \multicolumn{3}{|l|}{ Philippines } & \multirow{2}{*}{$\begin{array}{l}\text { Significance } \\
\text { of group } \\
\text { difference } \\
(p \text { value })\end{array}$} \\
\hline & $\begin{array}{l}\text { Mean or } \\
\text { percentage }\end{array}$ & $\mathrm{SD}$ & Range & $\begin{array}{l}\text { Mean or } \\
\text { percentage }\end{array}$ & SD & Range & $\begin{array}{l}\text { Mean or } \\
\text { percentage }\end{array}$ & $\mathrm{SD}$ & Range & \\
\hline \multicolumn{11}{|l|}{ Outcomes } \\
\hline Emotional problems & 1.33 & 0.31 & $1-2.38$ & 1.38 & 0.29 & $1-2.63$ & 1.24 & 0.25 & $1-2.65$ & $<0.001$ \\
\hline Physical aggression & 1.14 & 0.24 & $1-2.17$ & 1.19 & 0.26 & $1-2.83$ & 1.17 & 0.23 & $1-2.83$ & $<0.001$ \\
\hline \multicolumn{11}{|l|}{ Sociodemographic variables } \\
\hline Age $4-6$ & $64 \%$ & & $0-1$ & $43 \%$ & & $0-1$ & $64 \%$ & & $0-1$ & $<0.001$ \\
\hline Girl & $50 \%$ & & $0-1$ & $47 \%$ & & $0-1$ & $48 \%$ & & $0-1$ & 0.604 \\
\hline PMK with university degrees & $79 \%$ & & $0-1$ & $18 \%$ & & $0-1$ & $74 \%$ & & $0-1$ & $<0.001$ \\
\hline PMK married & $92 \%$ & & $0-1$ & $94 \%$ & & $0-1$ & $91 \%$ & & $0-1$ & 0.290 \\
\hline \multicolumn{11}{|l|}{ Universal predictors } \\
\hline Low income & $48 \%$ & & $0-1$ & $32 \%$ & & $0-1$ & $28 \%$ & & $0-1$ & $<0.001$ \\
\hline PMK depression & 1.64 & 0.48 & $1-3.69$ & 1.49 & 0.40 & $1-3.56$ & 1.48 & 0.39 & $1-3.75$ & $<0.001$ \\
\hline Positive family function & 3.86 & 0.39 & $2-5$ & 3.92 & 0.36 & $2.41-5$ & 4.07 & 0.36 & $1.83-5$ & $<0.001$ \\
\hline Neighbourhood cohesiveness & 3.21 & 0.53 & $1.40-5$ & 3.49 & 0.42 & $2-5$ & 3.45 & 0.55 & $1.8-5$ & $<0.001$ \\
\hline PMK social support & 3.28 & 0.62 & $1.86-5$ & 3.44 & 0.50 & $2.14-5$ & 3.54 & 0.57 & $1.71-5$ & $<0.001$ \\
\hline \multicolumn{11}{|l|}{ Migration-specific variables } \\
\hline PMK fluency in English/French & $22 \%$ & & $0-1$ & $22 \%$ & & $0-1$ & $54 \%$ & & $0-1$ & $<0.001$ \\
\hline PMK acculturation stress & 1.85 & 0.46 & $1-3.36$ & 1.73 & 0.42 & $1-4$ & 1.71 & 0.41 & $1-3.63$ & $<0.001$ \\
\hline PMK perceived prejudice & 2.85 & 0.60 & $1-5$ & 2.63 & 0.51 & $1-1.48$ & 2.52 & 0.53 & $1-4.67$ & $<0.001$ \\
\hline Ethnic concentration & 0.71 & 0.50 & $0-1$ & 0.63 & 0.46 & $0-1$ & 0.44 & 0.47 & $0-1$ & $<0.001$ \\
\hline
\end{tabular}

children were more likely than older to be physically aggressive, and boys more likely to display PA than girls. PMK depression was, once again, a significant predictor. Compared with Filipino children, PRC Chinese displayed less PA, and HK Chinese, more. Children in Toronto were at higher risk for PA than children in Vancouver. Although differences for the other two regions did not achieve statistical significance, the trend was similar to that observed for EP, with Toronto the setting characterized by the highest level of risk. Acculturation stress and perceived prejudice made significant and independent contributions to explaining physical aggressiveness scores.

\section{Discussion}

Methodological limitations must be acknowledged. The findings are based on three groups selected because, at the time the NCCYS began, they made up the largest proportion of immigrant children in Canada. They do not constitute a representative sample of all immigrant children, or even of the three countries of origin groups taking part in this study. The results should not, and cannot be generalized to all immigrant children. True probabilistic sampling of these difficult to locate, highly mobile populations will probably always be elusive. The aim of the NCCYS is not, however, to establish rates and to make cross-sample comparisons, but rather to investigate the impact of theoretically meaningful factors on the mental health of immigrant children through statistical modeling of putative risk and protective factors. Weighting has been used to help compensate for problems such as restricted variability.

There are also limitations stemming from the data and the analyses. The relatively large number of variables included, together with large sample sizes gives rise to the problem of alpha inflation. Rather than adopt a strategy such as restricting the definition of statistical significance to an arbitrary cut-off, this report presents findings using conventional levels of significance, leaving it to the reader to judge the substantive significance of the findings. Although the amount of variance explained compares favorably with amounts reported in other studies of similar populations [23], 15.6 and $9.1 \%$ leave a great deal of variance unaccounted for. Future NCCYS publications will include a much larger number of immigrant communities, thereby permitting examination of potentially important mental health risk factors such as separation from parents [11], and immigrant versus refugee status [16]. The fact that the PMK was the sole source of information may be another limitation, since other studies [31, 51] have demonstrated that children's self-reports evidence limited overlap with parent ratings. Relying on one source of 
Table 3 Regression of emotional problems on sociodemographic, universal and migration-specific predictors

\begin{tabular}{|c|c|c|c|c|c|c|}
\hline & \multicolumn{3}{|l|}{ Model 1} & \multicolumn{3}{|l|}{ Model 2} \\
\hline & $\mathrm{B}$ & $\beta$ & SE & $\mathrm{B}$ & $\beta$ & SE \\
\hline Intercept & $1.510 * * *$ & & 0.092 & $1.095 * * *$ & & 0.105 \\
\hline \multicolumn{7}{|l|}{ Sociodemographic variables } \\
\hline Age $4-6$ & -0.017 & -0.029 & 0.012 & -0.001 & -0.002 & 0.012 \\
\hline Girl & -0.015 & -0.025 & 0.012 & -0.012 & -0.021 & 0.012 \\
\hline PMK with university degrees & $-0.059 * * *$ & -0.099 & 0.013 & -0.017 & -0.029 & 0.015 \\
\hline PMK married & 0.003 & 0.003 & 0.023 & -0.015 & -0.014 & 0.023 \\
\hline \multicolumn{7}{|l|}{ Universal predictors } \\
\hline Low income & -0.007 & -0.011 & 0.013 & -0.003 & -0.004 & 0.013 \\
\hline Household income not reported & -0.010 & -0.006 & 0.037 & -0.027 & -0.016 & 0.037 \\
\hline PMK depression & $0.176^{* * * *}$ & 0.263 & 0.015 & $0.147 * * *$ & 0.219 & 0.017 \\
\hline Positive family function & $-0.102 * * *$ & -0.134 & 0.017 & $-0.079 * * *$ & -0.104 & 0.018 \\
\hline Neighbourhood cohesiveness & 0.005 & 0.009 & 0.012 & 0.012 & 0.022 & 0.013 \\
\hline PMK social support & -0.008 & -0.016 & 0.011 & $0.031^{*}$ & 0.063 & 0.014 \\
\hline \multicolumn{7}{|l|}{ Migration-specific variables } \\
\hline Mainland China & & & & 0.029 & 0.049 & 0.016 \\
\hline Hong Kong & & & & $0.107 * * *$ & 0.163 & 0.019 \\
\hline Prairies & & & & $-0.064 * *$ & -0.070 & 0.023 \\
\hline Montreal & & & & $-0.073 * *$ & -0.061 & 0.028 \\
\hline Vancouver & & & & $-0.055 * * *$ & -0.091 & 0.016 \\
\hline PMK fluency in English/French & & & & $-0.035^{*}$ & -0.057 & 0.014 \\
\hline PMK acculturation stress & & & & $0.062 * * *$ & 0.093 & 0.017 \\
\hline PMK perceived prejudice & & & & $0.030^{*}$ & 0.059 & 0.012 \\
\hline Ethnic concentration & & & & 0.004 & 0.006 & 0.013 \\
\hline Adjusted $R^{2}$ & 0.121 & & & 0.156 & & \\
\hline$N$ & 1,975 & & & & & \\
\hline
\end{tabular}

$* p<0.05, * * p<0.01, * * * p<0.001$

Total $n<2,031$ due to missing data

information may result in biased associations. For example, the association between PMK perceptions of prejudice and childhood distress may be a substantive finding reflecting the adverse effect of prejudice on everyone in the family, but it is also possible that the relationship is a confound stemming from the PMK's projection onto children of their own distress and their attributions regarding cause [51]. Future NCCYS reports will include children's self-reports, as well as data from their parents. Finally, because data for the current report are cross-sectional, they cannot address the question of causal sequencing. It is, for example, plausible that physically aggressive children disrupt family functioning, rather than the other way round. Future analyses employing NCCYS longitudinal data can help address this problem.

It seems that, in many ways, immigrant children's mental health is affected by the same factors that affect the mental health of children in general. For example, consistent with results from other studies, boys are more likely than girls, and younger children more likely than older, to display PA [22, 33, 41, 43]. As is the case for children in general, parental depression increases the risk for childhood EP [24, 29]. However, in contrast with studies that have focused on "mainstream" populations [23, 28], neighbourhood characteristics had no demonstrable effect on the mental health of immigrant children. Perhaps the neighbourhoods in which immigrants live during the early years of resettlement do not offer sufficient variability to demonstrate statistically significant associations. A more substantive explanation is also possible. Some authorities $[25,27]$ have suggested that family factors trump neighbourhood characteristics as predictors of children's mental health.

Consistent with other reports [7, 57], this study demonstrates that, despite the stresses of resettlement, immigrant children manage to stay in relatively good mental health. Low income, one of the most powerful mental health risk factors for children in general $[7,54,55]$, had no 
Table 4 Regression of physical aggression on sociodemographic, universal and migration-specific predictors

\begin{tabular}{|c|c|c|c|c|c|c|}
\hline & \multicolumn{3}{|l|}{ Model 1} & \multicolumn{3}{|l|}{ Model 2} \\
\hline & $\mathrm{B}$ & $\beta$ & SE & $\mathrm{B}$ & $\beta$ & SE \\
\hline Intercept & $1.161 * * *$ & & 0.079 & $1.012 * * *$ & & 0.091 \\
\hline \multicolumn{7}{|l|}{ Sociodemographic variables } \\
\hline Age 4-6 & $0.083 * * *$ & 0.169 & 0.011 & $0.091 * * *$ & 0.186 & 0.011 \\
\hline Girl & $-0.056 * * *$ & -0.116 & 0.011 & $-0.054 * * *$ & -0.112 & 0.010 \\
\hline PMK with university degrees & $-0.035 * *$ & -0.071 & 0.011 & -0.009 & -0.019 & 0.013 \\
\hline PMK married & -0.029 & -0.032 & 0.020 & -0.037 & -0.041 & 0.020 \\
\hline \multicolumn{7}{|l|}{ Universal predictors } \\
\hline Low income & -0.010 & -0.021 & 0.011 & 0.006 & 0.013 & 0.011 \\
\hline Household income not reported & -0.031 & -0.022 & 0.032 & -0.057 & -0.040 & 0.032 \\
\hline PMK depression & $0.071 * * *$ & 0.127 & 0.013 & $0.058 * * *$ & 0.103 & 0.015 \\
\hline Positive family function & -0.029 & -0.046 & 0.015 & -0.029 & -0.046 & 0.015 \\
\hline Neighbourhood cohesiveness & 0.019 & 0.042 & 0.011 & 0.014 & 0.030 & 0.011 \\
\hline PMK social support & -0.008 & -0.020 & 0.010 & 0.018 & 0.044 & 0.012 \\
\hline \multicolumn{7}{|l|}{ Migration-specific variables } \\
\hline Mainland China & & & & $-0.049 * * *$ & -0.100 & 0.014 \\
\hline Hong Kong & & & & $0.036^{*}$ & 0.065 & 0.016 \\
\hline Prairies & & & & -0.037 & -0.049 & 0.019 \\
\hline Montreal & & & & -0.046 & -0.046 & 0.024 \\
\hline Vancouver & & & & $-0.063 * * *$ & -0.124 & 0.014 \\
\hline PMK fluency in English/French & & & & 0.001 & 0.002 & 0.012 \\
\hline PMK acculturation stress & & & & $0.036^{*}$ & 0.065 & 0.014 \\
\hline PMK perceived prejudice & & & & $0.020^{*}$ & 0.048 & 0.010 \\
\hline Ethnic concentration & & & & 0.002 & 0.005 & 0.011 \\
\hline Adjusted $R^{2}$ & 0.063 & & & 0.091 & & \\
\hline$N$ & 1,975 & & & & & \\
\hline
\end{tabular}

$* p<0.05, * * p<0.01, * * * p<0.001$

Total $n<2,031$ due to missing data

significant association with either EP or PA among HK, PRC and Filipino immigrant children in this study. Previous research reports $[7,27]$ have noted that poverty had a less powerful effect on children's mental health among immigrant, than among native-born children. One possible interpretation is that poverty is a different experience for immigrants and native-born children and their families. Single parent and dysfunctional family status, for example, are frequent concomitants of poverty among native-born, but not among immigrant families [7].

The PMK's in these samples had remarkably low levels of proficiency in English or French. According to official reports [20], about one-third or more of immigrants speaks neither language on arrival. The rates for PMK's in this study were much higher, ranging from 50 to almost $80 \%$. One reason for the discrepancy is that most of the PMK's were mothers. In most immigrant families, the father is the principal applicant, and he must achieve a certain score in order to qualify for admission. Language proficiency is an important component of this score. Other members of the immediate family do not have to pass the so-called "points" test. Lack of linguistic fluency among mothers apparently had an adverse effect on children, perhaps because lack of language compromises adult mental health [16] or perhaps because it gives rise to role reversal-a situation in which children, who learn the language and culture of resettlement countries more quickly than their parents, may be called upon to negotiate with the larger society in ways usually reserved for adults $[16,47]$. Canada provides English or French language training for newcomers, but the limited duration of the classes, inappropriate mix of students, and barriers limiting women's participation $[8,13,21]$ compromise program effectiveness.

In view of the many studies attesting to the importance of the like-ethnic community in supporting the mental 
health of adult immigrants $[3,9]$, the lack of association between this variable and children's mental health is surprising. Perhaps the operational measure of ethnic concentration failed to do justice to the underlying construct. Another possibility is that "neighbourhood" in this study referred to geographical community, whereas people may define community in other ways that are more relevant for their mental health. Finally, a like-ethnic presence may be less salient for young children than it is for adolescents and adults.

One of the study's aims was to investigate possible mental health effects of region of resettlement. Given Toronto's reputation as a multicultural city, it is surprising that it is the place in which immigrant children apparently experience the greatest mental health risk. Previous research [12] demonstrating that, in comparison with other provinces, Quebec was less accepting of immigrants would lead to the prediction that Montreal would occupy the position Toronto assumes in the current study. However, that study's data are now more than 15 years old, and secular changes may have affected attitudes towards immigrants. In the early 1990s, immigration began acquiring increasing cachet in Quebec, the Prairies and British Columbia. For example, in 1991, the federal government signed an accord with Quebec, devolving jurisdiction as well as funding for settlement and integration to the Province. Similar accords were signed with Manitoba in 1996, with British Columbia in 1998, and with Alberta in 2002. By contrast, during the mid- to late 1990s, Ontario provided severely limited amounts of the kinds of social support that many immigrant families require during the early years, remained cool towards immigrants, and suspicious of federal policies of devolution. It was not until 2004 that the province signed an initial letter of intent to proceed with negotiations regarding immigrant selection, destination and integration. Despite being the largest magnet for immigrants, Ontario may not have presented the most welcoming environment. Future NCCYS studies will attempt more in-depth explorations of the relationships between region of resettlement and children's well-being.

The study's results demonstrate the importance of unpacking overly broad categories such as "immigrant children" or even "Asian immigrants." PRC children experienced a lower risk of developing problems than either HK or Filipino youngsters. These findings call attention to the circumstances of migration, in particular the phenomenon of transnational families. Filipino migration is often initiated by women who travel abroad to respond to the needs for trained personnel by some countries or to take advantage of special situations such as Canada's "fast track" path to landed immigrant status. When family reunification takes place, often after a prolonged separation, it can be complicated by children's resentment over perceived maternal abandonment $[1,11$, 45]. Many HK families apparently come to Canada with plans to stay long enough to ensure their children' education, but with the ultimate goal of returning to the home country [35, 44]. Authorities [11, 44, 52] have raised concerns about the possible mental health consequences of prolonged parental absences, and of pursuing the goal of return rather than of integration. Although it is tempting to speculate that the increased mental health risk among HK Chinese and Filipino children may be at least partially attributable to parental absences consequent on transnationalism, drawing such conclusions would be premature. For one thing, such an interpretation would be open to the ecological fallacy-to attributions based on group characteristics that may or may not apply to study subjects themselves. Future NCCYS studies will focus on relationships between parental absences and children's mental health risk. Since family separation is, to a certain extent, amenable to changes in policy, these results cast a potentially important light on the importance of speeding up family reunification. With respect to services, if children in transnational families are indeed subject to particular mental health risk, meeting their needs may call for special training programs for service providers, including the need to plan for family life post-reunification [11].

The over-riding significance of the study lies in demonstrating that migration-specific variables influence the well-being of the children of immigrants, net of factors that affect the mental health of most, if not all children, Future research and intervention programs should take account of the specificity of mental health risk and protective factors on the lives of children in immigrant families

Acknowledgments This paper is a product of the New Canadian Children and Youth Study (Principal Investigators: Morton Beiser, Robert Armstrong, Linda Ogilvie, Jacqueline Oxman-Martinez, Joanna Anneke Rummens), a national longitudinal survey of the health and well-being of more than 4,000 newcomer immigrant and refugee children living in Montreal, Toronto, Winnipeg, Edmonton, Calgary and Vancouver. The NCCYS is a joint collaboration between university researchers affiliated with Canada's four Metropolis Centres of Excellence for research on immigration and settlement, and community organizations representing Afghani, Hong Kong Chinese, Mainland Chinese, Latin American (El Salvadorean, Guatemalan, Colombian), Ethiopian, Haitian, Iranian, Kurdish, Lebanese, Filipino, Punjabi, Serbian, Somali, Jamaican, Sri Lankan Tamil, and Vietnamese newcomers in Canada. Major funding for the project has been provided by the Canadian Institutes for Health Research (CIHR grants FRN-43927 and PRG-80146), Canadian Heritage, Citizenship and Immigration Canada (CIC), Health Canada, Justice Canada, Alberta Heritage Foundation for Medical Research, Alberta Learning, B.C. Ministry of Social Development and Economic Security, B.C. Ministry of Multiculturalism and Immigration, Conseil Quebecois de la Recherche Sociale, Manitoba Labour and Immigration, and the Montreal, Prairies, and Ontario Metropolis Centres of Excellence for research on immigration and settlement. 


\section{References}

1. Asis MMB (2002) From the life stories of Filipino women: personal and family agendas in migration. Asian Pacifc Migr J 11:67-94

2. Asis MMB, Huang S, Yeoh BSA (2004) When the light of the home is abroad: unskilled female migration and the Filipino family. Singap J Trop Geogr 25:198-215

3. Aylesworth LS, Ossorio PG, Osaki LT (1977). Stress and mental health among Vietnamese in the United States: preliminary findings of a mental health needs assessment among Vietnamese refugees in Colorado. Paper presented at the Health, Education and Welfare Conference on Mental health needs of Indochinese refugees, Denver, $\mathrm{CO}$

4. Badets J, Chard J, Levett A (2003) Ethnic diversity survey. Portrait of a multicultural society, Statistics Canada, cata. No. 89593-XIE. http://www.statcan.gc.ca

5. Barker ED, Tremblay RE, Nagin DS (2006) Development of proactive and reactive aggression during adolescence. J Child Psychol Psychiatry 47(8):783-790

6. Beiser M, Fleming JAE (1096) Measuring psychiatric disorder among Southeast Asian refugees. Psychol Med 16:627-639

7. Beiser M, Hou F, Hyman I, Tousignant M (2002) Poverty and mental health among immigrant and non-immigrant children. Am J Public Health 92(2):220-227

8. Beiser M, Hou F (2001) Language acquisition, unemployment and depression among Southeast Asian refugees: a 10-year study. Soc Sci Med 53:1321-1334

9. Beiser M (1999) Strangers at the gate. University of Toronto Press, Toronto

10. Beiser M, Noh S, Hou F, Kaspar V, Rummens J (2001) Southeast Asian Refugees' Perceptions of racial discrimination in Canada. Can Ethnic Stud 33(1):46-70

11. Bernhard JK, Landolt P, Goldring L (2008) Transnationalizing families: Canadian immigration policy and the spatial fragmentation of care-giving among Latin American newcomers. Int Migr 47(2):3-31

12. Berry JW, Kalin R (1995) Multicultural and ethnic attitudes in Canada: an overview of the 1991 National Survey. Can J Behav Sci 27(3):301-320

13. Boyd M (1992) Gender issues in immigration and language fluency. In: Chiswick BR (ed) Immigration, language and ethnicity: Canada and the United States, the AEI Press, Washington DC, pp 305-372

14. Boyle MH, Offord DR, Racine YA, Fleming JE et al (1993) Evaluation of the revised Ontario Child Health Study scales. J Child Psychol Psychiatry 34(2):189-213

15. Bronfenbrenner U (1995) Developmental ecology through space and time: a future perspective. In: Moen P, Elder GH Jr, Luscher $\mathrm{K}$ (eds) Examining lives in context: perspectives on the ecology of human development. APA Books, Washington DC

16. Canadian Task Force on Mental Health Issues Affecting Immigrants and Refugees (1988) After the door has been opened (Cat. No. Ci96-38/1988E). Ministry of Supply and Service, Ottawa

17. Chen AB (1990) Studies on Filipinos in Canada: State of the Art. Canadian Ethnic Studies 22(1):83-96

18. Chen AB (1999) Filipino, in multicultural history society of Ontario: encdyclopedia of Canada's peoples. University of Toronto Press, Toronto

19. Chui T, Tran K, Flanders J (2005). Chinese Canadians: enriching the cultural mosaic, Canadian Social Trends, Statistics Canada, cat. No. 11-008, Ottawa, pp 24-32

20. Citizenship and Immigration Canada, Facts and Figures (2006). Immigration overview: permanent residents, http://www.cic.gc. ca/EnGLIsh/resources/statistics/facts2006/permanent/12.asp-38k
21. Citizenship and Immigration Canada (2004) Evaluation of the language instruction for newcomers to Canada (LINC) program. http://www.cic.gc.ca/english/resources/evaluation/linc/findings. asp

22. Cohen P, Cohen J, Kasen S, Velez CN, Hartmark C, Johnson J, Rojas M, Brook J, Streuning EL (1993) An epidemiological study of disorders in late childhood and adolescence: I. Age- and gender-specific prevalence. J Child Psychol Psychiatry 34:851867

23. Curtis LJ, Dooley M, Phipps SA (2004) Child well-being and neighbourhood quality: evidence from the Canadian longitudinal study of children and youth. Soc Sci Med 58(10):1917-1927

24. Downey G, Coyne JC (1990) Children of depressed parents: an integrative review. Psychol Bull 108:50-76

25. Ellen IG, Turner MA (1997) Does neighbourhood matter? Assessing recent evidence. Housing Policy Debate 8(4):833-866

26. Fleming JE, Boyle MH, Offord DR (1993) The outcome of adolescent depression in the Ontario child health study follow-up: longitudinal studies of depressive disorders in children. J Am Acad Child Adolesc Psychiatry 32(1):28-33

27. Georgiades K, Boyle MH, Duku E (2007) Contextual influences on children's mental health and school performance: the moderating effects of family immigrant status. Child Dev 78(5):15721591

28. Ginther D, Hveman R, Wolfe B (2000) Neighbourhood attributes as determinants of children's outcomes. J Human Resources 35(4):603-642

29. Goodman SH, Brogan D, Lunch ME, Fielding B (1993) Social and emotional competence in children of depressed mothers. Child Dev 64:516-531

30. Hou F, Beiser M (2006) Learning the language of a new country: a ten-year study of English acquisition by Southeast Asian refugees in Canada. Int Migr 44(1):135-165

31. Janssen MMM, Verhulst FC, Bengi-Arsian L, Eroi N, Salter CJ, Alfons A, Crinjen M (2004) Comparison of self-reported emotional and behavioral problems in Turkish immigrant, Dutch and Turkish adolescents. Soc Psychiatry Psychiatr Epidemiol 39(2):133-140

32. Leavey G, Hollins K, King M, Barnes J, Papadopoulos C, Grayson K (2004) Psychological disorder amongst refugee and migrant schoolchildren in London. Soc Psychiatry Psychiatr Epidemiol 39:191-195

33. Lee KH, Baillargeon RH, Vermunt J, Wu HX, Tremblay RE (2007) Age differences in the prevalence of physical aggression among 5-11 year old Canadian boys and girls. Aggress Behav 33:26-37

34. Le Espritu Y (2002) Filipino navy stewards and Filipino health care professionals: immigration, work and family relations. Asian Pacific Migr J 11:47-66

35. Ley D, Kobayashi A (2005) Back to Hong Kong: return migration or transnational sojourn? Glob Networks 5:111-127

36. Li PS (1998) Chinese in Canada, (second edition). Oxford University Press, Toronto

37. Li PS (1999) Chinese in multicultural history society of Ontario: encyclopedia of Canada's peoples. University of Toronto Press, Toronto

38. Martinez CR, McClure HH, Eddy JM (2009) Language brokering contexts and behavioral and emotional adjustment among Latino parents and adolescents. J Early Adolesc 29(1):71-98

39. Mesch GS (2003) Language proficiency among new immigrants: the role of human capital and societal conditions: the case of immigrants from the FSU in Israel. Soc Perspect 46(1):41-58

40. Mirsky J (1997) Psychological distress among immigrant adolescents: culture-specific factors in the case of immigrants from the former Soviet Union. Int J Psychol 32(4):221-230 
41. Nagin DS, Trembaly RE (2001) Parental and early childhood predictors of persistent physical aggression from kindergarten to high school. Arch Gen Psychiat 58(4):389-394

42. Noh S, Beiser M, Kaspar V, Hou F, Rummens J (1999) Perceived racial discrimination, depression and coping: a study of Southeast Asian refugees in Canda. J Health Soc Behav 40:193-207

43. Offord DR, Lipman EL (1996) Emotional and behavioural problems. In: Human Resources and Skills Development Canada and Statistics Canada (ed) Growing up in Canada: National Longitudinal Survey of Children and Youth, vol. 1, cat. No 89555-MPE, Ottawa, Human Resources and Skills Development Canada

44. Orellana MF, Thorne B, Chee A, Lam WSE (2001) Transnational childhoods: the participation of children in processes of family migration. Soc Problems 48:572-591

45. Pe-puna RC, Mitchell C, Iredale R, Castles S (1996) Astronaut families and parachute children: the cycle of migration between Hong Kong and Australia, Centre for Multicultural Studies, University of Wollongong, Wollongong

46. Schmalzbauer L (2004) Searching for wages and mothering from afar: the case of Honduran transnational families. J Marriage Family 66:1317-1331

47. Sluzki CE (1979) Migration and family conflict. Fam Process 18:379-390

48. Statistics Canada (2008). 2006 census data products. Ethnic origins, 2006 Counts for Canada, release date April 2, 2008, cata. No. 97-562-XWE2006002

49. Statistics Canada and Human Resources Development Canada (1995) National longitudinal survey of children: overview and survey instruments for 1994-1995; data collection cycle 1 . Ministry of Industry, Ottawa
50. Thompson SK, Seber GAF (1996) Adaptive sampling. Wiley, New York

51. Vollebergh WAM, ten Have M, Dekovic M, Oosterwegl A, Pels T, Veenstra R, de Winter A, Ormel H, Verhulst F (2005) Mental health in immigrant children in the Netherlands. Soc Psychiatr Psychiatr Epidemiol 40:489-496

52. Waters JL (2003) "Sattlelite kids" in Vancouver: transnational migration, education and the experiences of lone children. In: Charney M, Yeoh BSA, Tong CK (eds) Asian migrants and education: the tension of education in immigrant societies and among migrant groups. Kluwer Academic Publishers, London, pp $165-184$

53. Watters JK, Biernacki P (1989) Targeted sampling: options for the study of hidden populations. Soc Problems 36(4):416-430

54. Whitbeck LB, Hoyt DR, Simon RL, Conger RD, Elder GH, Lorenz FO et al (1992) Intergenerational continuity of parental rejection and depressed affect. J Pers Soc Psychol 63:1036-1045

55. Wickrama KAS, Conger RD, Abraham W (2005) Early risk and later health. The intergenerational transmission of socioeconomic adversity through mental disorder and physical illness. J Gerentol (a special issue) 60B:125-129

56. Woodward LJ, Fergusson DM (2000) Childhood and adolescent predictors of physical assault: a prospective longitudinal study. Criminology 38:233-261

57. Wu Z, Hou F (2009) Racial diversity, minority concentration and trust in Canadian urban neighbourhoods. Soc Sci Res 38(3):693716

58. Ying YW, Han M (2008) Parental contributions to Southeast Asian American adolescents' well-being. Youth Soc 40:289-306 